\title{
Percepção dos Discentes de Administração acerca da relação entre Teoria e Prática o Centro Acadêmico do Agreste
}

\author{
Jucilaine Laiara de Oliveira SILVA
}

Universidade Federal de Pernambuco (UFPE/CAA), Caruaru, PE, Brasil

Maria Maryana de Oliveira SOARES

Universidade Federal de Pernambuco (UFPE/CAA), Caruaru, PE, Brasil

Ana Márcia Batista Almeida PEREIRA

Universidade Federal de Pernambuco (UFPE/CAA), Caruaru, PE, Brasil

Received 27 Fev. 20; Accepted 17 Mar. 20

Evaluation System: Double Blind Review

Editor: Jose Lindenberg Julião Xavier Filho, $\mathrm{Dr}$. ISSN: $2594-8040$

To cite this paper: Silva, J. L. O., Soares, M. M. O., \& Pereira, A. M. B. A. (2020). Percepção dos discentes de administração acerca da relação entre teoria e prática no Centro Acadêmico do Agreste. Journal of Perspectives in Management-JPM, 4, p. 2-14.

\section{Resumo}

O debate sobre a relação entre teoria e prática compõe a formação profissional e acadêmica dos discentes de Administração. Nessa conjuntura, esse estudo objetiva descrever a percepção dos estudantes de Administração sobre a relação entre teoria e prática vivenciadas ao longo da formação acadêmica. Para tanto, optou-se por uma pesquisa qualitativa com a aplicação do grupo focal como técnica. Durante o grupo, no início, os estudantes expuseram a teoria e prática como dissociadas. Posteriormente, foram analisando com mais rigor e modificaram algumas ideias pré-concebidas. Este estudo contribui com a literatura acadêmica já que traz a visão dos estudantes sobre a temática.

Palavras-Chave: Teoria; Prática; Administração. 


\section{Introdução}

A visão dicotômica entre teoria e prática é comum em todos os âmbitos, incluindo as ciências administrativas. $\mathrm{O}$ debate entre os termos vem ocorrendo ao longo do tempo por vários estudiosos. Contudo, recebeu influências do senso comum desde a civilização ocidental (Mattos, 2010)

No ensino de Administração, essa discussão se sustenta no questionamento de como as teorias aprendidas em sala de aula são colocadas em prática no mercado de trabalho, de acordo com Pinto, Conte, Silva e Coronel (2015). Sendo assim, essa discussão entre os termos não se restringe apenas aos pesquisadores, mas aos próprios discentes do curso de Administração. Segundo Nassif, Ghobril e Bido (2007, p. 12):

Considerando o ensino de Administração como um processo de aprender para criar e fazer, tendo em vista que o resultado desta aprendizagem reflete-se no desempenho das próprias organizações, pensar a teoria e a prática de maneira fragmentada e independente tem gerado uma formação deficiente, ou seja, gestores com dificuldade de aplicar os conhecimentos adquiridos na Universidade no exercício da gestão administrativa.

Diante disso, a compreensão dos termos por parte dos discentes é essencial durante sua formação acadêmica. Entretanto, essa é uma das preocupações dos educadores e profissionais da área, pois reconhecem que uma compreensão equivocada dos termos pode resultar em uma formação deficiente. Sendo assim, a percepção dos discentes de Administração acerca dos termos teoria e prática precisa estar dentro de um parâmetro que possa contribuir positivamente para a sua formação e também para a inserção no mercado de trabalho.

Se a percepção é o modo como os indivíduos organizam e interpretam as impressões sensoriais para dar sentido ao ambiente, o que um indivíduo percebe, pode ser diferente da percepção de outro indivíduo (Robbins, 2005). Dessa forma, nota-se que a dicotomia entre os termos pode estar presente no contexto de sala de aula influenciando, de alguma forma, a percepção dos estudantes. Diante da problemática apresentada, este artigo busca responder à seguinte questão de pesquisa: qual é a percepção dos discentes de Administração do Centro Acadêmico do Agreste na Universidade Federal de Pernambuco (CAA/UFPE) acerca da relação teoria e prática ao longo da sua formação acadêmica?

Ao constatar que a dicotomia entre os termos teoria e prática é uma discussão presente há algum tempo entre os vários campos de conhecimento, especialmente na Administração, fica claro o quanto é viável elaborar um estudo acerca desse tema. Nassif, Ghobril e Bido (2007, p. 12) dizem: "o debate sobre teoria e prática e sua integração no contexto educacional como fonte de geração de conhecimento não é recente." Essa discussão que motivou muitos estudiosos ao longo dos anos, também nos motivou com o intuito de compreender como esse debate influencia os discentes de Administração durante sua formação acadêmica, além de tentar compreender a percepção desses estudantes acerca dos termos. Ainda segundo Nassif, Ghobril e Bido (2007), integrar a teoria à prática na sala de aula é sempre um desafio. Ademais, será de grande importância para área das ciências sociais aplicadas, pois pretendemos analisar como essa dicotomia se faz presente no contexto de sala de aula. Sob essa ótica, manifestam-se os seguintes objetivos específicos: (1) identificar a compreensão dos discentes sobre os termos teoria e prática; (2) caracterizar a relação teoria-prática durante a formação acadêmica em Administração na Universidade; por fim, (3) averiguar as consequências da percepção dos estudantes acerca dos termos teoria e prática na sua aprendizagem.

Para alcançar o propósito anunciado, este artigo está organizado para apresentar esta introdução; em seguida, alguns apontamentos sobre o debate teoria-prática nas ciências administrativas; os procedimentos metodológicos com ênfase na estratégia do focus group; posteriormente, a discussão dos resultados e, por fim, algumas considerações. 


\section{Referencial Teórico}

Neste capítulo, será recuperado, brevemente, o debate acerca da relação teoria e prática, situando-o nas ciências administrativas, e apontadas as suas conexões com a formação no ensino superior na área.

\subsection{Um breve histórico sobre teoria e prática}

O debate entre a dicotomia da teoria e prática recebeu influências do senso comum desde a civilização ocidental e, portanto, não foi criado na Administração (Mattos, 2010). Na cultura clássica grega, iniciou-se uma dicotomia entre o saber e atuar (teoria e prática) que se consolidou e permeou o pensamento moderno, como salientado por Mattos (2010) ao destacar a acertada reflexão feita por Carlos Bertero em 2004. Platão, em sua época, reiterava a discrepância entre o teórico e o prático ao afirmar: "o importante é a ideia". Paralelamente, Aristóteles reafirmava que a filosofia e ciência eram um saber teórico, elegendo como "ciência primeira" (Pereira, 1984).

Atualmente, veem-se reflexos da visão clássica em frases cotidianas e de senso comum como: "na teoria é uma coisa, mas, na prática, é outra". Contudo, Pereira (1984) demonstra que essa visão supracitada - sob a ótica da filosofia clássica e do senso comum - está equivocada, pois teoria e prática são caminhos convergentes. Ou seja, apesar de se constituírem como conceitos diferentes, sua separação não é absoluta e, portanto, deve-se analisá-los sob outra perspectiva.

Assim, para entender a teoria e prática são necessários alguns cuidados: (1) abandonar os simplismos dos conceitos. Apesar de se conectarem, não são a mesma coisa; (2) entender que a teoria está além da lógica e é uma questão antropológica. O homem não apenas cria a teoria, como está inserido nela. "Ao mesmo tempo em que a prática é pressuposto básico ou fundamento da teoria, ela não pode ser entendida separadamente da teoria. Senão, seria ação animalizada e não ação humana" (Pereira, 1984, p. 74).

Assim, romper com o dualismo teoria-prática em nível mais profundo significaria rever uma cultura filosófica e científica. Por mais desafiante que pareça dizer, nós ocidentais estivemos teoricamente equivocados, por milênios, sobre o sentido de nossa própria linguagem, por assim dizer "ofuscados" por ela própria; tratamo-la como meio a serviço de formas mentais; dissociamo-la da ação de pensar, restringindo-a à "fase" da expressão e criando, por isso, "sujeito" (o pensante) e "objeto" (o pensado) divorciados, quando, de fato, a linguagem é que viabilizava ambos (Mattos, 2010, p. 7).

Ante o exposto, historicamente a sociedade distanciou a teoria e a prática e isso permeou os conhecimentos científicos e filosóficos de tal forma que a Administração, enquanto uma ciência social aplicada incorporou os reflexos desse equívoco milenar.

\subsection{Relação teoria-prática em Administração}

A discussão sobre teoria e prática vem ocorrendo há muito tempo entre diversas áreas de conhecimento, como foi analisado. Desde que a Administração se constituiu como campo científico essa discussão se tornou uma preocupação para os pesquisadores dos estudos organizacionais. Entretanto, segundo Pinto et al. (2015), esse debate é direcionado na tentativa de questionar se o que é preconizado por teorias e aprendido em sala de aula pode ser colocado em prática nas empresas dentro do mercado de trabalho. Sendo assim, é a partir dessa visão que o conflito entre teoria e prática na Administração foi construído.

De acordo com Nassif, Ghobril e Bido (2007), os educadores e profissionais da área de ciências sociais aplicadas, especialmente da Administração, têm demonstrado crescente preocupação com o assunto, porém, há pouca literatura sobre metodologias de ensino que dão respostas para integração entre teoria e prática na sala de aula nos cursos de Administração. Sendo 
assim, percebemos que o debate entre teoria e prática vai além das salas de aula, interferindo direta ou indiretamente nas organizações.

Essa discussão sobre teoria e prática também recebe influências do pensamento comum.

Começa-se com o entendimento de senso comum sobre teoria e prática. Embora há tempo tenha sido ultrapassada pelos desenvolvimentos na filosofia da ciência social, a maior parte dos leigos (e não poucos analistas organizacionais) subscreve essa visão e, apenas por tal razão, ela deve ser seriamente considerada. De acordo com essa visão, a "teoria" recorre ao mundo do pensamento e reflexão, enquanto a "prática" recorre ao mundo da ação, do fazer coisas. Teoria e prática são interpretadas como diferentes (Marsden \& Townley, 2001, p. $31)$.

A compreensão sobre teoria e prática é necessária para que não haja uma aprendizagem deficiente por parte dos discentes, ademais, é importante compreender que a integração entre esses dois termos é relevante ao longo da formação acadêmica. Nassif, Ghobril e Bido (2007, p. 12) dizem: "pensar a teoria e prática de maneira fragmentada e independente tem resultado na formação deficiente, ou seja, gerando profissionais com dificuldade de aplicar os conhecimentos adquiridos na Universidade no exercício da gestão administrativa".

Atualmente, devido à visão separatista da teoria e prática, a produção científica em Administração está sendo analisada como destinada a pesquisadores, e não detentora de conhecimentos úteis aos gestores. "Se o conteúdo que produzimos e disseminamos é ignorado, por que o fazemos? Para que serviria a produção de conhecimento científico em Administração, senão para munir os praticantes?" (Mascarenhas, Zambaldi, \& Moraes, 2011, p. 275). Mais uma vez, a percepção de que a teoria é distante da realidade, no mundo organizacional, corrobora na dicotomia teoria-prática. Quando, na verdade, a prática, na percepção humana, é um modelo/abstração da realidade então, desse modo, é teoria. "Com isso, não há prática isenta de teoria que a corrobore: é no âmbito teórico que a prática se legitima. Portanto, a prática, na prática, é uma representação teórica!" (Terra, Ganzert, Medeiros \& Passador, 2013, p. 14).

Dessa forma, nota-se que a percepção que os estudantes têm acerca da relação teoria-prática é capaz de impactar negativamente na sua formação e gerar danos de longo prazo, inclusive, dentro das organizações. Essa visão limitada que gera uma dicotomia entre os termos vem percorrendo há muitos anos. Sendo assim, necessita de uma ação que deve ser iniciada dentro da experiência em sala de aula.

\subsection{A integração teoria-prática na formação acadêmica dos administradores ${ }^{i}$}

Tendo em vista que a teoria e a prática estão atreladas, não se pode medir qual se sobressai, pois são complementares, e uma formação acadêmica que não une esses dois conceitos é insuficiente. Segundo Dias Junior, Moreira, Stosick e Pereira (2014, p. 173) "o distanciamento da academia com a realidade provoca um verdadeiro abismo entre o que é aprendido em sala e os conhecimentos e habilidades que, de fato, os alunos necessitam na prática empresarial". Assim, o curso de Administração deve procurar promover essa integração aos estudantes.

A aplicação da prática na sala de aula é uma dificuldade encontrada em qualquer nível da educação brasileira, pois há uma "cultura" de aulas expositivas.

Historicamente, o ensino no Brasil caracteriza-se por aulas expositivas como a única forma de transmissão de conhecimento e a realização de provas como a única forma de avaliação e verificação da aprendizagem, isto é percebido desde a educação básica até a educação superior. Os estudantes e docentes se acostumaram com esta metodologia e, em muitas vezes, não percebem que podem existir outros métodos de ensino que permitam complementar o que é abordado na sala de aula (Parente, Cabral, Andrade, Bonadies \& Pessoa, 2009, p. 4). 
Essa distância da sala de aula com a realidade contribui para a definição estereotipada de teoria e prática citada anteriormente. A constância em buscar um meio de aproximar a experiência em sala de aula do mundo organizacional, aquece o debate entre os discentes e docentes acerca de como efetuar essa integração.

Para minimizar tal descompasso, utilizam-se várias alternativas para que o estudante se insira numa atmosfera onde ele vivencie o ambiente de trabalho ao mesmo tempo que reflita sobre o que está aprendendo em sala de aula. Dentre as possibilidades de vivência de ambiente de trabalho, o estágio curricular, a empresa júnior, as dinâmicas usadas em sala de aula (estudo de casos, role playing, por exemplo), são maneiras que ajudam o estudante a transpor a teoria aprendida em sala de aula para o universo do trabalho organizacional ou para uma simulação dele (Franco, 2006, p. 16).

Com isso, observamos que há várias maneiras de se integrar a teoria e prática, além do estágio como componente curricular. A prática também deve ser vista na sala de aula, não só em campo. Deve-se buscar uma equidade acerca da transmissão da teoria e prática, para que não haja um desfalque na formação acadêmica do futuro administrador.

Contudo, como foi mencionado em Pinto et al. (2015), o debate no curso superior em Administração busca questionar se o que é preconizado por teorias e aprendido em sala de aula pode ser colocado em prática nas empresas dentro do mercado de trabalho, corroborando para o debate entre os discentes e docentes sobre aproximar a experiência em sala de aula com o mundo organizacional. Entretanto, essa integração precisa de ações transformadoras, ações essas que catalisem práticas docentes cujo foco seja uma maior integração dos estudantes na construção do conhecimento. Assim, " "a Universidade deve rediscutir as dimensões qualitativas da relação teoria e prática, sem limitar-se apenas ao espaço da sala de aula, (...) mas indo além do espaço acadêmico", (Nassif, Ghobril, \& Bido, 2007, p. 12).

Por ser uma ciência social aplicada, muitos autores defendem a tese de que a Administração deve exceder os limites da sala de aula. Entretanto, apesar de haver muitas vezes uma valorização da prática em detrimento da teoria, o pilar prático, na formação acadêmico-profissional, unicamente não se sustenta, pois sem o conceito teórico o sujeito é incapaz de possuir um olhar crítico acerca das situações que exigem reflexões e que o contexto organizacional possui.

No Brasil, o Conselho Nacional de Educação, através da Resolução no 4, de 13 de julho de 2005, instituiu as Diretrizes Curriculares Nacionais do Curso de Graduação em Administração, no bacharelado, que orientam a elaboração do Projeto Pedagógico do Curso (PPC). No Centro Acadêmico do Agreste da Universidade Federal de Pernambuco, o PCC indica alguns objetivos do processo de ensino-aprendizagem:

Construção de competências e habilidades para trabalhar em estudos administrativos, organizacionais, estratégicos, qualitativos e quantitativos nas diversas áreas da Administração, tais como: gestão da produção e serviços, recursos humanos, comercialização e marketing, finanças, gestão tecnológica, ambiental, comércio exterior, gestão da informação, e suas metodologias;

Habilitar o profissional para trabalhar nas áreas sociais, econômicas, políticas, culturais, relações internacionais, investigação científica, e suas metodologias; - Proporcionar a capacitação para lidar com temas transversais, tais como: gênero, transculturalismo, globalização da economia, desenvolvimento, qualidade de vida no trabalho, entre outros (UFPE, 2010, p. 15).

Como observado, as competências do administrador não se restringem apenas à ação no ambiente organizacional, mas envolvem também o estudo das mesmas. Segundo o Art. $1^{\circ}, \S 1^{\circ}$, o Projeto Pedagógico do curso deverá abranger sem prejuízo de outros: modos de integração entre teoria e prática. É possível entender que o Conselho considera ambas importantes e que, portanto, 
devem se integrar durante a formação acadêmica em Administração, na finalidade de efetivar as competências e habilidades requeridas ao administrador.

Segundo Zarifian (2003, p. 137 apud Regio, Schuch Jr., Gomes e Kneipp, 2012, p. 146), “é importante destacar que competência é uma inteligência prática, aplicada às situações reais, que se apóia em conhecimentos adquiridos, os quais se transformam na medida em que as ações são desenvolvidas". Com isso, pode-se refletir que, se competência é uma inteligência prática, e as competências do curso de Administração envolvem também o trabalho em estudos, a prática vai além das habilidades técnicas que serão aplicadas no âmbito organizacional. A problemática surge porque existe uma cortina estereotipada que divide a teoria como útil aos estudantes que desejam a área acadêmica, enquanto que a prática é vista como imprescindível aos estudantes que desejam atuar diretamente na prática organizacional. Contudo, aqueles que desejam atuar na gestão das organizações, precisarão da teoria para desenvolver uma pesquisa de mercado, por exemplo. Enquanto os futuros acadêmicos também precisarão compreender a prática organizacional para formular suas pesquisas acadêmicas.

Diante do exposto, é importante compreender a relação teoria-prática no âmbito da formação acadêmica qualificada como um processo dialético e que também fundamenta a educação ética e transformadora, nos termos de Freire (1996), cuja reflexão crítica sobre a prática inclui a experiência concreta dos discentes.

\section{Procedimentos Metodológicos}

Nesta seção, será explicitado o design da pesquisa, orientado pelo objetivo do estudo.

\subsection{Delineamento da pesquisa}

Trata-se de pesquisa qualitativa, pois "responde a questões muito particulares, pois se preocupa, nas ciências sociais, com um nível de realidade que não pode ser quantificado", como afirma Minayo (2002, p. 21). Portanto, quanto à natureza, o presente estudo foi qualitativo já que o objetivo geral da pesquisa buscou descrever a percepção dos discentes acerca da relação entre teoria e prática, no curso de Graduação em Administração. Ao analisar Gil (1999, p. 94), vê-se que há uma reafirmação da adequação da pesquisa ao método qualitativo ao dizer que "[...] métodos de pesquisa qualitativa estão voltados para auxiliar os pesquisadores a compreenderem pessoas e seus contextos sociais, culturais e institucionais".

Quanto aos meios de investigação, utilizou-se a pesquisa de campo cuja investigação é realizada em um local que dispõe de elementos para explicar o fenômeno estudado (Vergara, 2000), sendo acionada a estratégia de focus group, sendo a técnica de pesquisa que produz o material empírico por meio da entrevista coletiva. Quanto aos fins, a pesquisa foi descritiva, visto que, em geral, caracterizou a relação teoria-prática, expondo as visões dos estudantes a esse respeito (Vergara, 2000).

\subsection{Seleção dos sujeitos}

Na presente investigação, os participantes foram selecionados com base na conveniência do acesso e importância para a execução da pesquisa, além de outros critérios, tais como: (1) ser estudante do curso de Graduação em Administração da Universidade Federal de Pernambuco, no Centro Acadêmico do Agreste; (2) ter disponibilidade para participar do grupo focal. Do total, 6 (seis) são mulheres e 3 (três) são homens, estão na faixa etária de 18 a 22 anos, e cursam o $3^{\circ}$ e $4^{\circ}$ períodos. Logo, não houve participação de estudantes "veteranos" e alguns eram do mesmo círculo de amizade, tendo sido estas as limitações da pesquisa. Os 9 (nove) sujeitos foram denominados: S1, S2, S3, S4, S5, S6, S7, S8 e S9, com vistas a preservar o anonimato. 


\subsection{Plano de produção do material empírico}

A produção do material empírico realizou-se por meio da técnica do grupo focal, que busca diferentes percepções sobre um fato a partir da interação entre os membros do grupo. "A essência do grupo focal consiste justamente na interação entre os participantes e o pesquisador, que objetiva colher dados a partir da discussão focada em tópicos específicos e diretivos (por isso é chamado grupo focal)." (Lervolino \& Pelicioni, 2001, p. 116). Ademais, segundo Minayo (2009), essa técnica é muito usada no trabalho de campo qualitativo e consiste em reuniões com um pequeno número de interlocutores (seis a doze). Exige-se a presença de um animador e um relator. O animador tem o papel de focalizar o tema, promover a participação de todos, inibir os monopolizadores da palavra e aprofundar a discussão. Já o relator, além de auxiliar o coordenador nos aspectos organizativos, deve estar atento para anotar todo o processo criativo e interativo.

Dessa forma, o grupo focal se tornou mais viável à pesquisa do que outra técnica. Segundo Borges e Santos (2005), o grupo focal possui determinados procedimentos que se diferenciam de outras entrevistas grupais. Para o planejamento dessa técnica devem ser considerados alguns itens: no recrutamento dos participantes, é ideal que os integrantes não pertençam ao mesmo círculo de amizade ou trabalho; o recrutamento ocorre em função do grupo social a ser estudado, devendo abranger sua variabilidade; o local no qual será realizado o grupo deve ser neutro, acessível e silencioso; a duração média de um grupo focal é de uma hora e trinta minutos; além do roteiro de entrevista conter em suas questões os temas-chave a serem investigados, inicia-se por questões gerais e, em seguida, abordam-se as específicas.

O grupo focal foi agendado antecipadamente com os 9 (nove) participantes e realizou-se nas dependências do CAA/UFPE no dia 27 de setembro de 2019 com duração de uma hora.

\section{Discussões dos Resultados ${ }^{\mathrm{ii}}$}

No presente estudo, com a finalidade de iniciar o debate, primeiramente, foram expostas algumas imagens através do projetor, como por exemplo: fotos que representavam estudantes dentro da sala de aula, estagiários em locais de trabalho, professores ministrando aulas, indivíduos com livros à mão, entre outras. Dessa forma, o intuito da pesquisa, utilizando esse viés inicial de abordagem, era provocar uma descontração nos discentes para que se sentissem à vontade e pudessem verbalizar seus conhecimentos e suas percepções acerca da teoria e da prática. Posteriormente, iniciou-se uma roda de conversa baseada em pauta específica definida pelo coordenador, com o propósito de: (1) identificar a compreensão dos discentes sobre os termos teoria e prática; (2) caracterizar a relação teoria-prática durante a formação acadêmica em Administração na Universidade; por fim, (3) averiguar as consequências da percepção dos estudantes acerca dos termos teoria e prática na sua aprendizagem.

Os participantes iniciaram interpretando e relacionando as imagens expostas as suas compreensões acerca dos termos teoria e prática. À medida que cada integrante explicitava sua opinião, o moderador da discussão exibia as imagens lentamente para que os participantes pudessem captar o máximo de informações possível para embasar seus argumentos. Os sujeitos foram questionados se as imagens poderiam ser divididas em duas colunas: a coluna A representava a teoria e a coluna $\mathrm{B}$, a prática. Respondendo positivamente à pergunta, o (a)s entrevistado(a)s alocaram as imagens de acordo com sua percepção. Ao longo do debate, os estudantes começaram a reformular seus argumentos usados inicialmente. De modo simultâneo, os relatores anotavam cada etapa da discussão e as opiniões dos entrevistados. Paralelamente, houve uma abertura para os participantes trocarem experiências entre si visando à construção de um ambiente descontraído, sem a pressão de atingir um plano conclusivo ou um consenso de opiniões (Lervolino, \& Pelicioni, 2001).

Ao expor a primeira imagem, com dois homens trabalhando em uma empresa, S5 e S6 apresentam visões semelhantes: 
É um cenário que realmente expõe a prática, colocando na prática o que tá aprendendo na teoria (S5, entrevista em 27.09.19).

Vejo um ambiente de prática, um ambiente de tomada de decisões (S6).

S5 e S6 atrelaram a imagem projetada apenas a um ambiente de prática, na qual se vivencia a teoria aprendida. Entretanto, essa é uma visão que difere da opinião de S7 quando afirma:

Eu não consigo dissociar a prática da teoria. Não sei qual tipo de serviço que eles fazem, e nem quais teorias estão usando (S7).

Para S7, a imagem projetada apresenta um ambiente de prática, mas sem ser fragmentado da teoria. Difere de S5 e S6 que excluem a teoria desse ambiente. Ao dar seguimento ao debate, foi projetada uma imagem de uma sala de aula levantando a percepção de outras participantes.

Acredito que esteja mais atrelada à teoria, devido ao ambiente de aprendizagem. E, segundo o que a gente já estudou também, a questão da relação da teoria e prática, que a teoria tá mais atrelada a passar aquela informação e não a praticar mesmo (S9).

$\mathrm{Na}$ minha opinião, fica na teoria. Estão todos ali sem realizar nenhuma ação, apenas recebendo conhecimento, e não estão praticando nada (S4).

A segunda imagem projetada, de acordo com S9 e S4, relaciona-se com a teoria, visto que estão apenas compartilhando informações e conhecimentos, e não estão realizando nenhuma ação. Entretanto, para S8 há outros elementos que precisam ser analisados. Para o mesmo, o ambiente de sala de aula remete à teoria, mas pode haver a prática dependendo da didática do docente e da disciplina.

Teoria. Como estão em sala de aula, o objetivo é o ensino e a gente relaciona muito à teoria, mas também pode haver prática, dependendo do professor, da disciplina, e da didática do professor (S8).

Com o avanço na pauta do debate, os entrevistados expuseram que, a depender do professor, até a aprendizagem pode ser afetada devido à dissociação entre teoria e prática. O S5 expressa tal situação:

Eu não tinha parado pra pensar que uma pesquisa, projeto de pesquisa ou até mesmo um seminário podem ser "prática". Acredito que o professor tem que deixar claro que aquilo é uma prática porque tem aluno que absorve o assunto como uma mera informação. $\mathrm{O}$ aluno realmente precisa entender que aquilo é uma situação que ele vai encontrar no mercado de trabalho e aquilo se torna uma prática de alguma forma (S5).

De acordo com o relato acima é perceptível que, caso o professor não explicite que o conteúdo debatido em sala de aula também se interliga com o mundo organizacional, o estudante poderá internalizar a visão de senso comum na qual a prática é definida como ação e que essa prática - através de estágio ou trabalho - será a ponte de ligação para o mundo organizacional, e não o conteúdo ministrado em sala de aula. Por conseguinte, o estudante tenderá a negligenciar esses assuntos em sala porque acredita que a Administração é prática (ação) e a aula ministrada pelos professores dificilmente se interligará com o exercício da profissão. O S6 reforça que a separação entre os termos é comum e se encontra no cotidiano, conforme já apontado por Mattos (2010):

Eu acho que é uma questão cultural. Estamos muito acostumados a separar esses termos. Os alunos tendem a ligar a prática à ação e quando o professor convida para uma pesquisa, ele não tem a noção de que aquilo também é prático. E isso é o que a pesquisa de vocês busca 
fazer. Afinal, como lidar com essa situação? Como trazer esse questionamento para sala de aula e influenciar esses alunos a serem mais dedicados a suas atividades? (S6).

Outra problemática pode ser encontrada na posição citada acima: a separação entre os termos cria uma divisão, na universidade, entre os potenciais pesquisadores ligados à teoria através de projetos de pesquisa e potenciais gestores ligados à prática através de disciplinas ou projetos de empreendedorismo. Sob essa ótica, os estudantes são, de certo modo, incentivados a escolherem um dos caminhos: pesquisa ou gestão. Tal conflito corrobora para a seguinte reflexão: se é necessário separar o pesquisador do gestor por que se faz pesquisa em Administração? Reflexão esta que remete à discussão colocada por Mascarenhas, Zambaldi e Moraes (2011). Afinal, o intuito da pesquisa deveria ser auxiliar os gestores na tomada de decisões nas organizações. O S1 confirma através da sua opinião que, de fato, essa separação está presente, uma vez que afirma que as pesquisas e projetos da Universidade são exclusivamente para os estudantes que anseiam a carreira acadêmica e de pesquisador:

Aqui, na federal, existe um incentivo ao estudante seguir a carreira acadêmica (S1)

S9, ao fazer um resgate histórico, percebeu que a dicotomia ocorre desde a formação escolar e, consequentemente, traz resquícios para a formação acadêmica. Tais resquícios podem afetar os futuros administradores nos seus postos de trabalho. Entretanto, segundo Pinto et al. (2015), é preciso que Administração enquanto ciência, bem como prática gerencial tenha o alinhamento entre teoria e prática para almejar sucesso nesses dois âmbitos.

Principalmente, no ensino médio e fundamental já era muito claro que existia uma separação: aula de laboratório é prática e sala de aula é teoria. Ou seja, nós já tínhamos essa bagagem de separar. Quando a gente entra em um curso como esse, a gente traz essa dificuldade (S9).

Diante desses relatos, podemos perceber que a maioria dos discentes acredita que os termos teoria e prática são fragmentados e dissociáveis um do outro. Apesar de alguns estudantes terem uma compreensão diferente, outros apresentam uma visão reducionista, afetando negativamente no seu processo de aprendizagem, pois passam a ter visões restritivas sobre teoria e prática. Sendo assim, compreendemos que a percepção fragmentada e independente dos termos tem gerado uma deficiência na formação acadêmica dos discentes, como ressalta Pinto et al. (2015).

Ao longo da discussão, outras questões foram levantadas. Uma delas foi a capacidade dos estudantes perceberem onde se vivencia a teoria e a prática no ambiente acadêmico, especialmente no curso de administração da UFPE no Centro Acadêmico do Agreste. Alguns participantes expuseram suas visões:

Depende do que o professor passa (...). A universidade tem o ensino e extensão, que aí se vê a prática, não só o ensino (S5).

Acho que nada é puramente teórico, sempre vai haver a prática. Depende muito do ponto de vista e de como ela é aplicada. Muitas vezes a gente apenas vê a parte teórica, porque a gente fica nessa caixa, preso de que prática é só quando você vai fazer alguma coisa. Em um estudo de caso, você tá colocando em prática as teorias que você está aprendendo (S9).

Estou no terceiro período e até agora só vi teoria. Talvez a prática seja na cadeira de estágio (S3).

Percebeu-se que, no decorrer do debate, os sujeitos foram alterando a percepção sobre teoria e prática e, antes, o que era distinto passou a ser integrado e dependente. No início, quando as imagens foram projetadas, os estudantes separaram a teoria da prática. Com o aprofundamento do debate no grupo focal, ficou notável, através das respostas acima, que os estudantes passaram a sentir certa dificuldade em definir com clareza o que realmente é teoria e prática, já que ambas se 
mostram interligadas, na linha de argumentação trazida por Pereira (1984). S7 ratifica essa mudança de percepção após o debate:

Eu acho que com esse debate a gente conseguiu identificar que temos bastante dificuldade em separar o que seria prática e teoria e, a partir desse debate, poderíamos estimular bastante gente a se dedicar. Às vezes entramos e saímos da disciplina sem entender o porquê de estudarmos aqueles assuntos. Talvez, se soubéssemos a importância daquele conteúdo e sua relação com o dia a dia, nossa visão também seria outra (S7).

A partir dessa linha de pensamento que Parente et al. (2009) afirmam que um dos papéis das universidades e dos docentes é proporcionar aos estudantes métodos adequados que facilitem o aprendizado. Além de proporcionar um ensino que tenha o objetivo de contemplar a prática, devido ao caráter aplicado desta ciência que é a Administração.

\section{Considerações Finais}

O debate sobre a relação teoria-prática tem sido objeto de atenção dos acadêmicos na área das ciências administrativas, visto que se insere nas especificidades da produção de conhecimento na área, impacta na formação dos estudantes, notadamente de graduação, mas também afeta a prática gerencial nas organizações. Este artigo procurou trazer à tona apontamentos sobre o debate teórico combinados à pesquisa de natureza qualitativa com o intuito de (1) identificar a compreensão dos discentes sobre os termos teoria e prática; (2) caracterizar a relação teoria-prática durante a formação acadêmica em Administração na Universidade; e, por fim, (3) averiguar as consequências da percepção dos estudantes acerca dos termos teoria e prática na sua aprendizagem. A produção do material empírico ocorreu por meio da realização de focus group com a participação de estudantes do curso de graduação em Administração do CAA/UFPE.

O estudo identificou que os estudantes possuem a visão da teoria como um fator relacionado ao campo das ideias enquanto a prática estaria interligada à ação e, entre as duas, a ação representaria maior importância. Os estudantes enfatizaram a necessidade de prática e mencionaram que estudam teoria em excesso. Logo, no processo de formação, os entrevistados associam a teoria aos conteúdos específicos das matérias e a prática às experiências de estágio, à resolução de estudos de caso em sala de aula, às atividades de extensão universitária, aos projetos de empreendedorismo. Este distanciamento teoria-prática influencia na aprendizagem dos estudantes, em geral, no sentido de não se sentirem estimulados a estudar ou mesmo não conseguirem visualizar as conexões da formação com as experiências concretas dentro e fora do mercado de trabalho.

Como se destacou no debate teórico, a teoria e a prática se equiparam em grau de importância na formação acadêmica do administrador e ambas não podem ser entendidas separadamente. O exercício do olhar atento e crítico contribui para entender que é possível construir pontes entre as duas e esta sensibilização aconteceu durante a experiência do focus group nesta pesquisa, sendo uma técnica que favoreceu o diálogo e a reflexão coletiva sobre o tema.

Diante disso, os resultados encontrados no presente estudo sugerem a extrema importância de um debate acerca dos termos teoria e prática, no contexto de sala de aula, entre discentes e docentes no curso de Administração da UFPE no CAA. Dessa forma, uma discussão clara sobre esses termos permitirá que os estudantes se desfaçam do senso comum e sejam capazes de compreender o vasto campo que uma visão relacional pode acrescentar ao longo de sua formação acadêmica, e também os ajudará a assumirem a posição de sujeitos críticos e reflexivos no processo de aprendizagem.

Como visto anteriormente, a fragmentação desses termos é capaz de contribuir para uma formação limitada. Além disso, o conhecimento restrito acerca da teoria e da prática, não só prejudica ao longo da formação, mas afeta direta ou indiretamente a inserção no mercado de trabalho. Sendo assim, a resposta positiva para essa problemática é proporcionar aos estudantes uma metodologia de ensino na qual possam perceber que os termos são convergentes e interrelacionados. Ademais, novas estratégias de ensino que permitam uma rediscussão na relação teoria e prática 
contribuirão positivamente para o conhecimento dos estudantes e, consequentemente, para a experiência em sala de aula que fundamenta o primeiro contato com o mundo organizacional.

Desse modo, provavelmente, as oportunidades de pesquisas proporcionadas na Universidade serão analisadas sob outra ótica e, outrossim, a separação entre pesquisadores e gestores seria minimizada, na medida do possível. Para isso, além dos debates supracitados, faz-se necessário investir em mais pesquisas relacionadas a essa temática no propósito de compilar os estudos e criar soluções mais coesas de acordo com a problemática encontrada. Ademais, estudos que situem esse debate no contexto do Agreste Pernambucano e contribuam para fazer uma re-leitura localizada das teorias organizacionais faz-se também relevante.

\section{Referências}

Borges, C. D., \& Santos, M. A. (2005). Aplicações da técnica do grupo focal: fundamentos metodológicos, potencialidades e limites. Revista da Sociedade de Psicoterapias Analíticas Grupais do Estado de São Paulo, 6(1), 74-80.

Franco, A. P. (2006). Da sala de aula ao mundo empresarial: compreendendo a aprendizagem vivenciada em consultoria júnior (Dissertação de mestrado). Programa de pós-graduação em Administração, Universidade Federal de Pernambuco, Recife, PE, Brasil.

Freire, P. (1996). Pedagogia da autonomia: saberes necessários à prática educativa. São Paulo: Paz e Terra.

Gil, A. C. (1999). Métodos e técnicas de pesquisa social. São Paulo: Atlas.

Dias Junior, C. M., Moreira, B. C. M., Stosick, E. Z., \& Pereira, A. R. (2014). Desenvolvimento de Competências do Administrador: Um Estudo em Ambiente Simulado. Revista de Ciências da Administração, 16(38), p. 172-182.

Lervolino, S. A., \& Pelicioni, M. C. F. (2001). A utilização do grupo focal como metodologia qualitativa na promoção da saúde. Revista da Escola de Enfermagem da USP, 35(2), p. 115-21.

Marsden, R., \& Townley, B. (2001). Introdução: a Coruja de Minerva: Reflexões sobre a Teoria na Prática. In: Clegg, S. R., Hardy, C., \& Nord, W. R. (org.). Handbook de Estudos Organizacionais: Reflexões e Novas Direções. São Paulo: Atlas, v. 2, p. 31-56.

Mascarenhas, A., Zambaldi, F., \& Moraes, E. (2011). Rigor, Relevância e Desafios da Academia em Administração: Tensões entre Pesquisa e Formação Profissional. Revista de Administração de Empresas, 51(3), p. 265-279.

Mattos, P. L. C. L. de. (2010). "Relações Teoria-Prática" em Administração: o que Desaparece nesse Buraco Negro. In: Encontro Nacional de Pós-Graduação e Pesquisa em Administração (ENANPAD), XXXIV, 25-29 Set., Rio de Janeiro (RJ).

Minayo, M. C. (2015). Pesquisa Social: Teoria, Método e Criatividade. 34 ed. Petrópolis: Vozes.

Nassif, V., Ghobril, A., \& Bido, D. (2007). É Possível Integrar a Teoria à Prática no Contexto de Sala de Aula? Uma Resposta Através do Método Seminário Revisado Através da Pesquisa- Ação em um Curso de Administração. Revista de Ciências da Administração, 18(9), p. 11-34.

Parente, T. C., Cabral, A. C. A., Andrade, A. G., Bonadies, G. R. M., \& Pessoa, M. N. M. (2009). A importância da Prática no Ensino: a Opinião dos Alunos de Administração de uma Instituição de Ensino Superior. In: Encontro de Ensino e Pesquisa em Administração e Contabilidade (EnEPQ), II, 15-17 Nov., Curitiba, PR.

Pereira, O. (1984). O que é teoria. 3 ed. São Paulo: Brasiliense

Pinto, N. G. M., Conte, B. P., Silva, R. A., \& Coronel, D. A. (2015). A Discussão entre Teoria e Prática nas Ciências Administrativas: uma Análise das Dissertações do Programa de PósGraduação em Administração da Universidade Federal de Santa Maria. Revista de Administração de Roraima, 5(2), p. 285-299.

Regio, M., Schuch Jr., V. F., Gomes, C. M., \& Kneipp, J. M. (2014). Gestão de Competências Profissionais Na Formação De Administradores. Revista da Avaliação da Educação Superior, 19(1), p. 131-155. 
Robbins, S. P. (2005). Comportamento Organizacional. 11 ed. São Paulo: Pearson Prentice Hall.

Souza, J. A. G., Xavier Filho, J. L. J., Martins, A. F. S., Silva, J. S., \& Gomes, J. S. (2018). A Distância da Academia para o Mundo das Organizações: analisando a pesquisa e o ensino em administração a partir do perfil dos pesquisadores do EnANPAD. Revista de Administração do UNIFATEA, 16(16), p. 7-30.

Terra, L. A. A., Ganzert, C. C., Medeiros, M. L., \& Passador, J. L. (2013). Reflexões Sobre as Práticas de Pesquisa em Administração. Revista Administração em Diálogo, 15(3), p. 1-17.

Universidade Federal de Pernambuco, Centro Acadêmico do Agreste. (2010). Projeto Pedagógico do Curso de Administração. <https://www.ufpe.br/documents/39146/0/PPC+Administra\%C3\%A7\%C3\%A3o++CAA/3dc31014-bc77-4c5e-be0b-eb6b3a93a2f1.pdf>.

Vergara, S. C. (2000). Projetos e relatórios de pesquisa em Administração. 3. ed. Rio de Janeiro: Atlas.

Xavier, J. L. J., Martins, A. F. S., Sales, M. L., Souza, J. A. G., \& Lorêto, M. S. S. (2016). Faça o que digo e faça o que não faço: Evidências no pensamento administrativo brasileiro dos problemas que assolam o Ensino de Administração. Revista FFBusiness, 14(18), p. 1-24.

Xavier, J. L. J., Sousa, J. L., Franco, S. M., \& Paiva Junior, F. G. (2016). Por onde Trafegam as Pesquisas em Administração: Aborda-se 'teoricamente' o que não está lá ou 'não se enxerga' o explícito da Prática Organizacional? In: Encontro Nacional de Pós-Graduação e Pesquisa em Administração (ENANPAD), XL, 25-28 Set., Costa do Sauípe (BA).

\title{
Perception's students of business administration about the relation between theory and practice in Academic Center of Agreste
}

\begin{abstract}
The debate about the relation between theory and practice makes the professional and scholar formation of business administration students. In this context, the focus of this study is to describe the perception's students of business administration about the relation between theory and practice experienced throughout the scholar formation. Therefore, it has been chosen a qualitative research with the focal group as technical application. During the group, in the begining, the students exhibited theory and practice as decoupled. Afterwords, they were analysing with more rigor some preconceived ideas and thus modified. This study contributes to the scholar literature that already brings the students's vision about the theme.
\end{abstract}

Keywords: Theory; Practice; Business Administration.

Sobre os Autores

\section{Jucilaine Laiara de Oliveira SILVA}

Graduanda em Administração, Universidade Federal de Pernambuco/Centro Acadêmico do Agreste (UFPE/CAA).

Avenida Campina Grande, s/n, km 59, Nova Caruaru, Caruaru, PE, Brasil, CEP 55014-900.

E-mail: jucilaine.laiara19@gmail.com 


\section{Maria Maryana de Oliveira SOARES}

Graduanda em Administração, Universidade Federal de Pernambuco/Centro Acadêmico do Agreste (UFPE/CAA).

Avenida Campina Grande, s/n, km 59, Nova Caruaru, Caruaru, PE, Brasil, CEP 55014-900.

E-mail: oliveiramaryanaufpe@gmail.com

\section{Ana Márcia Batista Almeida PEREIRA}

Professora do curso de Administração da Universidade Federal de Pernambuco (UFPE), Centro Acadêmico do Agreste (CAA). Doutora em Administração, Pesquisadora do GEIA (Grupo de Estudos e Intervenções do Agreste/UFPE) e TDEPP (Grupo de Trabalho, Desenvolvimento e Políticas Públicas/UFCG).

Avenida Campina Grande, s/n, km 59, Nova Caruaru, Caruaru, PE, Brasil, CEP 55014-900.

E-mail: anabatistaalmeida@gmail.com

\footnotetext{
${ }^{\text {i }}$ Para um melhor aprofundamento sobre a relação entre o ensino, a pesquisa em administração e a prática gerencial nas organizações, consultar os estudos realizados por Xavier Filho et al. (2016a, 2016b) e Souza, Xavier Filho, Martins, Silva e Gomes (2018).

ii Esta seção visa à apresentação dos resultados, centrando-se numa descrição mais detalhada da dinâmica ocorrida no grupo focal em paralelo à discussão dos resultados, com vistas a tornar o texto mais compreensível.
} 